\title{
The interplay between knowledge-based competitiveness, people's good health and well-being: new empirical evidence from Central and Eastern European countries
}

\author{
Gratiela Georgiana Noja ${ }^{1}$ (D) - Alexandru Buglea ${ }^{2}$ - Ion Lala-Popa ${ }^{2}$. \\ Cecilia Nicoleta Jurcut ${ }^{2}$
}

Published online: 6 July 2020

(c) Springer Nature B.V. 2020

\begin{abstract}
The enhancement of countries' competitiveness represents an essential credential in current economic interventions, national policy frameworks and strategies, mainly in relation to sustainable economic development. This paper explores the drivers of competitiveness in Central and Eastern European Countries (CEECs) in the knowledge economy, and its further impact on economic welfare, with a particular focus on individuals' perceived good health and well-being (a good predictor of people's future use of the healthcare system and mortality risk and a benchmark for sustainable development). The dataset grasps 11 CEECs analyzed during the 2000-2018 lapse of time. The methodological endeavor is based on three econometric procedures encompassing macroeconometric models, structural equation modelling (SEM) and network analysis through Gaussian Graphical Models. Main findings entail that CEECs competitiveness is driven by the key coordinates of the knowledge economy, particularly tertiary education, employment in technology and knowledgeintensive sectors, and additional government financial support dedicated for research and development activities. Moreover, in a further complex setting, competitiveness increases under the impact of education, research, development and innovation leads to significant upwards in GDP per capita levels. However, the further linkages with individuals' good health and well-being, when considered as a consequence of welfare increase following knowledge-driven competitiveness, or as a direct impact of competitiveness increases, entail a downsized outcome in terms of individuals' perceived health. Our results provide solid grounds for the development of new tailored policies designed to enhance CEECs knowledge-driven competitiveness in a comprehensive framework, with benefit spillovers on sustainable economic development.
\end{abstract}

Keywords Global competitiveness $\cdot$ Knowledge economy $\cdot$ Well-being $\cdot$ Sustainable development $\cdot$ Econometric modelling

Electronic supplementary material The online version of this article (https://doi.org/10.1007/s1113 5-020-01015-4) contains supplementary material, which is available to authorized users.

Gratiela Georgiana Noja

gratiela.noja@e-uvt.ro

Extended author information available on the last page of the article 


\section{Introduction}

A country's competitiveness is undoubtedly one of the most widely used concepts in current economic policies, but also in national policy frameworks and strategy designs, particularly in relation to economic growth (Voinescu and Moisoiu 2015; Cohen and Soto 2007; Hanushek and Kimko 2000) and individual well-being (Schuller and Lidbom 2009; Balkyte and Peleckis 2010) and therefore it has been at the core of diverse strands of thought in literature, being analyzed from different perspectives. At the same time, however, despite the strong notoriety and pervasiveness of the competitiveness concept garnered over the years, there is still a keen need to develop new theory and practice. Hence, our paper contributes to the discussion and strengthens the literature with new comprehensive assessments that combine both sides of competitiveness drivers and their economic consequences in terms of welfare, perceived health and individual well-being. The paper thus provides new information for policy-makers, practitioners, and other researchers on the decisive role played by the knowledge-driven competitiveness in enhancing economic welfare and sustainable development of countries, particularly Central and Eastern European Countries (CEECs).

Competitiveness driven by knowledge, research, development and innovation represents a topical subject, being an uttermost credential for sustainable economic development, with important benefit spillovers on individuals since it ensures people's good health and wellbeing (increased quality of life through large-scale access to quality services, particularly sanitation and long-term care, education, renewable energy). The concept is even more relevant in the current context of the global public health risk brought by the coronavirus (covid-19) epidemic. While countries all over the world face massive health risks and subsequent economic risks due to the negative consequences of coronavirus especially on the global trade, travel and tourism industries, but also on labor markets since millions of jobs are endangered, a new debate is opened on the essential role that countries' knowledge driven competitiveness could play in ensuring the sustainability of the national economic systems.

In this paper, competitiveness is analyzed according to the World Economic Forum (WEF) country's competitiveness definition as "the set of factors, policies and institutions that determine the level of productivity of a country taking into account its level of development" (WEF 2017: 4). The productivity of a country is the main factor with influence on the return on investment that reflects the growth potential of the economy (Schwab and Sala-i-Martin 2017), being further configured as the ability of a country to maintain a high level of income.

Our research is centered on assessing the competitiveness drivers of Central and Eastern European Countries (CEECs) in the knowledge economy framework, their further impact on economic welfare (captured through the GDP per capita) and the interlinkages (direct, indirect, bidirectional, total) with people's good health and well-being (as benchmark for sustainable development). The methodological credentials configured by our research rely on three econometric techniques applied to test three work hypotheses on a panel comprising 11 CEECs, members of the European Union (EU), namely Bulgaria, Czech Republic, Croatia, Estonia, Latvia, Lithuania, Poland, Slovak Republic, Slovenia, Romania and Hungary, analyzed during the 2000-2018 lapse of time. The econometric procedures applied comprise: (1) multifactorial regressions processed through four estimation methods (robust regression, panel corrected standard errors, two-stage least squares and the generalized method of moments), (2) structural equation modelling (SEM) and (3) network analysis 
based on Gaussian Graphical Models (GGMs) processed through the Extended Bayesian Information Criteria with graphical lasso and partial correlation. The results obtained provide new empirical evidence to attest that knowledge-driven competitiveness is an uttermost milestone for economic welfare of CEECs, yet failing to contribute to the upward in individuals well-being captured within the paper through people's perceived good and very good health status.

Following a brief introduction on the relevance of the topic and novelty of the research endeavor, the rest of the paper is structured to encompass a set of underlying drivers of competitiveness and the relationship between knowledge-driven competitiveness and individuals well-being in a comprehensive theoretical framework detailed in Sect. 2. The research hypotheses, dataset, indicators and methodological endeavor are presented in Sect. 3. Final parts of the paper enhance the results obtained throughout the empirical analysis for each of the three econometric techniques applied (multifactorial models, structural equation modelling - SEM and Gaussian Graphical Models-GGMs), along with discussions and concluding remarks, complemented with additional information on the robustness of the results comprised in the "Appendix".

\section{Theoretical framework}

\subsection{Global competitiveness in the knowledge economy}

By setting the grounds for global competitiveness of countries, the World Economic Forum has defined the competitiveness as "a set of factors, policies and institutions that determine the level of productivity of a country taking into account its level of development" (WEF 2017: 4). Moreover, in the light of a number of ample debates regarding the competitiveness measurement, the World Economic Forum developed the Global Competitiveness Index (GCI) that is composed of 12 pillars, namely: "institutions, infrastructure, macroeconomic environment, health and primary education, higher education and training, goods market efficiency, labor market efficiency, financial market development, technological readiness, market size, business sophistication and R\&D innovation" (WEF 2017: 4).

The linkages between competitiveness and the knowledge economy have represented the core of numerous researches in the scientific literature (Schwab and Sala-i-Martin 2017; Dima et al. 2018; Castells 1996; Weggeman 2000). Dima et al. (2018: 3) entail that "competitiveness and knowledge represent two key elements for improving long-term economic development, innovation and sustainability" of EU countries. Bojan and Stanisic (2013) have identified a strong correlation between the knowledge economy development level captured by the Knowledge Economy Index and the competitiveness level proxied by the Global Competitiveness Index in Southeastern European countries. Sum and Jessop (2013) have grasped significant interlinkages between competitiveness, the knowledgebased economy and higher education, while exploring the upwards of competitiveness as a "knowledge brand". On the same lines, Durazzi (2019) outlined that higher education policies are a key element of national economic competitiveness and the patterns of high skill formation ensure a successful transition into the knowledge economy.

The knowledge economy is a relatively new developed concept that has brought the attention of various researchers in the last decade (Castells 1996; Weggeman 2000).

A critical analysis of the relevant literature allowed us to emphasize four main pillars of the knowledge economy framework: 
(1) an economic incentive and institutional regime that encourages liberalization in order to encourage competition, thus fostering entrepreneurship (Bosworth and Collins 2013);

(2) educated and skilled workers throughout their lifetime- according to Gorji and Alipurian (2011: 51) “lifelong learning improves people's capacity to develop as members of their communities, education and training increase social cohesion, reduce crime and improve income distribution. Lifelong learning comprises formal learning (schools, training institutions, universities), non-formal learning (on-the-job and household training), and informal learning (skills learned from family members or people in the community)". Cohen and Soto (2007) entail "statistically significant positive effects of education on economic growth", while Hanushek and Kimko (2000) also consider that the quality of education has positive effects on economic growth. In their study, Jorgenson and Stiroh (2000) further underline that high-skilled workers are more complementary to ICT, while low-skilled workers are substitutable.

(3) an effective innovative system - there are several researches that highlight the substantial positive effects of innovation on economic growth (Lederman and Maloney 2003; Guellec and Van Pottelsberghe de la Potterie 2001). Lederman and Maloney (2003) have applied panel data regression of 5-year averages over 53 countries and brought new evidence to attest that there is a directly statistical significant relation between the R\&D expenditure and GDP. Guellec and Van Pottelsberghe de la Potterie (2001) have also deployed a panel data analysis covering the OECD countries over the 1980-1998 lapse of time in order to evaluate the long-run impact of R\&D activities and financial support on multifactor productivity growth. The authors reveal important positive consequences (statistically significant estimated coefficients) of business, public and foreign $\mathrm{R} \& \mathrm{D}$ on productivity growth.

(4) a modern and adequate information infrastructure - certain researches point out that both ICT production and ICT employment lead to economic development (Pilat and Lee 2001; Oliner and Sichel 2000; Schreyer 2000).

By connecting the knowledge economy with country competitiveness, Dima et al. (2018) underlined the decisive influence of several knowledge economy indicators (proxied by the general expenditure on research and development, tertiary educational attainment, lifelong learning) on the competitiveness of the European Union (EU) Member States (MS) [captured by the Global Competitiveness Index (GCI)]. Their findings point to an extremely favorable impact of education, R\&D and innovation on EU countries' competitiveness, these credentials being the main drivers of competitiveness across the EU. Hence, the authors further entail that EU policy makers should consider new lifelong learning programs for the European employees and a focus on R\&D activities, a mixture that would significantly contribute to the increase in EU MS competitiveness.

At the same time, however, due to the significant dissimilarities between the EU MS in terms of the implementation of the knowledge economy fundamentals, economic welfare and competitiveness levels, there is a keen need for particular analyses on distinctive groups of EU countries, and our focus in on Central and Eastern European Countries (CEECs), as another topical subject merely debated in the scientific literature.

Latterly, the role of innovation as an instrument for increasing the global competitiveness in the knowledge economy has been largely debated in the theory and practice (Kiselakova et al. 2018; Menbere and Hekelova 2016; Herman 2018).

Kiselakova et al. (2018) studied the impact of R\&D financial support on the global competitiveness development of the Slovak Republic, but also of other countries from Central 
and Eastern Europe (CEE), members of the EU (CEE-EU-11). The authors used the Global Competitiveness Index (GCI) designed by the World Economic Forum to analyze the competitiveness of 11 EU MS in CEE and focused on the interrelations between the R\&D expenditure height (per capita) and the values of the GCI score for these countries during the 2007-2016 period. The study shows statistically significant positive effects of the R\&D expenditures growth on the competitiveness level, hence entailing the decisive importance of increased $R \& D$ financial allocations for improving the global competitiveness of the CEECs.

The study of Menbere and Hekelova (2016: 132) highlighted that "countries with an advanced level of tertiary education, training and a higher level of innovation activities tend to achieve a higher level of the GCI indicator compared to countries with lower levels of education and innovation performance".

Herman (2018) studied the effects of innovation and entrepreneurship on the national competitiveness of EU countries, in order to underline how innovation and entrepreneurship can influence the national competitiveness and inclusive development in these countries. The results of the comparative analysis show that there are significant differences between low-medium innovation performance countries and high and very high innovation performance countries in terms of competitiveness, innovative entrepreneurship, productive entrepreneurship and economic and inclusive development, fact which emphasizes the need to take specific actions to improve EU innovation performance, especially in the EU countries included in the low-medium innovation performance countries group for improving national competitiveness and implicitly increasing the level of development. The analysis results suggest that the high level of national competitiveness in some EU countries can be mainly explained by high level of innovation performance, high level of innovative and productive entrepreneurship.

Moreover, Krstić et al. (2019) examined the relationship between country competitiveness (captured through a set of selected indicators from the Global Competitiveness Report) and science (proxied through the Innovation pillar) in the knowledge economy. The authors provided new insights on the contribution of an increased science competitiveness to the national economy competitiveness level, thus reinforcing the decisive link between the knowledge economy and country competitiveness.

\subsection{The interplay between knowledge-based competitiveness and sustainable economic development (socio-economic welfare, people's good health and well-being)}

Nowadays, the permanent improvement of the quality of life, people's health and wellbeing for present and future generations significantly increases the role of sustainable development (Balkite and Tvaronavičiene 2010).

As defined by the Europe 2020 strategy (Balkite and Tvaronavičiene 2010: 1), sustainable growth refers at "building a resource efficient, sustainable and competitive economy, development of new processes and technologies, including green technologies, exploiting EU-scale networks, and reinforcing the competitive advantages of the businesses". Smart growth means the development of the economy based on knowledge, innovation and intellectual capital. Inclusive growth entails "empowering people through high levels of employment, skills investments, fighting poverty and modernizing labor markets, training and social protection systems so as to help people anticipate and manage change, and build a cohesive society" (Balkite and Tvaronavičiene 2010: 1). 
Sustainability also recalls the concept of circular economy and the interest from diverse strands of thought, researchers and policy makers in this topical subject is growing in both the EU and other parts of the world. The European Commission (2015) particularly highlights the fundamental importance of the transition to a more circular economy for developing a sustainable and competitive economy, thus enhancing the competitive advantages for Europe. The recent 2018 updates on the EU bioeconomy strategy, the European Commission (2018) explicitly references the term "circular bioeconomy" and acknowledges an action plan directed towards achieving a sustainable, circular bioeconomy, by combining the two sides of the circular economy and bioeconomy into a single approach (GeorgescuRoegen 1975; Giampietro 2019). Nonetheless, the EU strategy focuses on an integrated approach that encompasses the connections between economy, society and the environment. Geerken et al. (2019) have assessed the potential of a circular economy in open economies (focusing on the case of Belgium) through different methods, and suggested that the activities of the circular economy "will enhance the ongoing trend of reducing the share of primary sectors in economies", thus becoming a key credential of competitive advantage. Moreover, the impact of certain sectors of the economy on the emissions of chemical pollutants in the atmosphere needs to be critically downsized to support people's good health and well-being, as well as the sustainable economic development (Marcu et al. 2016).

Other approaches have also considered the relation between knowledge-based competitiveness and sustainable economic development. The study of Balkyte and Peleckis (2010) highlights the positive interconnections and bidirectional dependence between competitiveness and sustainable development. Feurer and Chaharbaghi (1994) developed a holistic definition of competitiveness, considering the sustainability fundamentals: "Competitiveness is relative and not absolute. It depends on shareholder and customer values, financial strength which determines the ability to act and react within the competitive environment and the potential of people and technology in implementing the necessary strategic changes. Competitiveness can only be sustained if an appropriate balance is maintained between these factors which can be of a conflicting nature".

The research of Lapinskiene (2011) underlined that the competitiveness level of a country's economy is strongly interconnected with the sustainability indicators. The author has shown that "for the developing countries, GDP growth should be maintained to increase the sustainability. GDP growth cannot be assured for the infinity, because when the country reaches a high level of welfare its growth rate usually decreases, though the same high level of competitiveness and sustainable development is maintained at a slower but constant rate" (Lapinskiene 2011: 434).

Even if the researchers were focused on the importance of achieving sustainability to ensure long-term competitiveness, there are also proposals in the scientific literature to evaluate the climate change or well-being aspects in the context of competitiveness (Balkite and Tvaronavičiene 2010).

The relationship between competitiveness and well-being is constantly transforming, nowadays being stronger and merely interconnected with knowledge-driven factors. It is important to identify the most relevant drivers of the economic growth and the living standards to further depict the role played by knowledge-driven competitiveness in enhancing socio-economic welfare and individual well-being. Countries which are highly ranked regarding competitiveness are even highly ranked regarding living standards (Schuller and Lidbom 2009). Huggins and Thomson (2017: 23) denote that competitiveness must be considered through its "connections with wider development goals beyond economic growth, such as those related to social development, well-being and the sustainable development of regions". The authors reveal that, in general, regions with higher levels of competitiveness 
are associated with increased levels of well-being, while regions with low competitiveness achievements encapsulate negative externalities associated with lower levels of well-being. On these lines, Runiewicz-Wardyn (2018) has also explored how competitiveness and well-being interlink in a sustainable development framework, by referring to the case of the Central and Eastern European countries. The author concludes that "improving competitiveness contributes to the overall levels of well-being in these countries" (RuniewiczWardyn 2018: 1) and that "promoting social inclusiveness as well as the greener and more sustainable economy is equally important in order to sustain their growth and shift their specializations from labor-intensive to more capital- and technology-intensive sectors" (Runiewicz-Wardyn 2018: 16).

The role of intellectual capital, education, innovation and national health is highlighted in numerous articles related to competitiveness and various indicators have been used to analyze the impact of these drivers on national competitiveness, as well as the further spillover effects on socio-economic welfare, people's good health and well-being. Using databases from developed, emerging and developing nations, the study of Herciu and Ogrean (2015) underlined strong interrelations between national wealth, national competitiveness and national intellectual capital, that lead to increased sustainable economic development and well-being. Furthermore, by encompassing the perceptions of competitiveness in the context of sustainable development, Balkyte and Tvaronavičiene (2010) make use of the "sustainable competitiveness" notion and highlight that "continued competitiveness and economic growth are essential factors for supporting living standards and wellbeing. Strong international competitiveness creates the resources that enable material improvements in living standards and resources for investments that promote both individual wellbeing and national competitiveness" (Balkyte and Tvaronavičiene 2010: 342).

One of the most relevant drivers with positive impact on the country's innovative potential development is the amount of released public investment. The paper of Simionescu et al. (2017) underlined the drivers of economic growth and the role played by competitiveness in this respect by reporting to V4 countries and Romania. Their results confirmed the favorable impact of competitiveness, but also a bidirectional linkage since higher economic growth attracted more foreign investors.

Şener and Saridogan (2011: 815) have also analyzed the impact of science-technology-innovation oriented global competitiveness strategies, along with the associated mechanisms of transmission, on the economic growth of high income countries. The authors brought new evidence to attest that nations with "science-technology-innovation oriented global competitiveness strategies are determining sustainable competitiveness and long term economic growth".

\section{Research hypotheses, data and methodology}

\subsection{Research hypotheses}

After reviewing the literature and setting the groundings of our own methodological endeavor, we configured three work hypotheses $(\mathrm{H})$ in order to be tested, namely:

- Hypothesis $\mathbf{1}\left(\mathbf{H}_{1}\right)$ CEECs competitiveness is positively driven and enhanced by the knowledge economy fundamentals, namely tertiary education, research and development and innovation; 
- Hypothesis $2\left(\mathbf{H}_{2}\right)$ There are significant positive implications of CEECs knowledgedriven competitiveness on economic welfare and individuals' well-being;

- Hypothesis $3\left(\mathbf{H}_{3}\right)$ There are substantial impacts and interlinkages between economic welfare driven by knowledge based competitiveness and individuals' perceived health and well-being (sustainable development).

\subsection{Data and indicators}

In line with the clear-cut double objective of our research endeavor centered on assessing the drivers of competitiveness in countries from Central and Eastern Europe, and its further impact on economic welfare and public health of individuals residing in these countries, we have performed an extensive empirical analysis on a newly compiled dataset comprising 11 economies and a set of key indicators captured during the 2000-2018 lapse of time.

The indicators are selected following a detailed literature review [by considering the work of Dima et al. (2018), Bojan and Stanisic (2013), Gorji and Alipurian (2011), Lederman and Maloney (2003), Guellec and Van Pottelsberghe de la Potterie (2001), Kiselakova et al. (2018), Menbere and Hekelova (2016), Krstić et al. (2019), Balkyte and Peleckis (2010), Herciu and Ogrean (2015), Simionescu et al. (2017), which have also used several of these indicators as proxies in their studies on the same subject, with accurate results] and encompass:

- the Global Competitiveness Index $(G C I)$ - as developed by the World Economic Forum;

- Real GDP per capita (GDP_cap) — "the ratio of real GDP to the average population of a specific year", euro/capita;

- People with good and very good perceived health $(P G H)$ (Self-perceived health, ages 16 years or over), \%;

- Intramural R\&D expenditure (GERD) by sectors of performance (all sectors), \% of GDP;

- Employment in technology and knowledge-intensive sectors at the national level (HTech) (NACE_R2- “High-technology sectors: high-technology manufacturing and knowledge-intensive high-technology services), \% of total employment";

- Lifelong learning $(L L L)$ — "Participation rate in education and training (last 4 weeks)", all ISCED levels, ages 18-74 years, \%;

- Population by educational attainment level-Tertiary education (TE), levels 5-8, ages from 30 to 34 years, \%;

- Patent applications (Patents) to the EPO by priority year, number.

For a unitary approach and relevant comparison, the main database used for collecting the data was Eurostat (European Commission 2020). Summary statistics of all considered indicators are synthesized in Table 1 .

GCI, GDP_cap and PGH are three key indicators that we have analyzed and considered within the empirical analysis as proxies for the fundamental coordinates considered throughout the research endeavor, namely competitiveness $(G C I)$, sustainable economic growth $\left(G D P \_c a p\right)$ and individual health and well-being $(P G H)$.

Within the European Union, there is a significant discrepancy between the EU Member States in terms of competitiveness levels (Fig. 1a). Hence, we note that in 2018 CEECs countries have registered the lowest levels of competitiveness compared to the other EU 
Table 1 Summary statistics of selected indicators deployed in the empirical analysis. Source: Authors' contribution in Stata 16

\begin{tabular}{llccll}
\hline & $N$ & Mean & \multicolumn{1}{l}{ Sd } & Min & Max \\
\hline GCI & 164 & 4.358961 & 0.2464709 & 3.67 & 5.12 \\
GDP_cap & 207 & 10426.28 & 3735.785 & 3010 & 20170 \\
PGH & 149 & 57.12349 & 8.151218 & 35 & 70.9 \\
GERD & 207 & 0.9366667 & 0.4817867 & 0.36 & 2.56 \\
HTech & 121 & 3.628099 & 1.067491 & 1.7 & 5.9 \\
LLL & 165 & 11.53333 & 3.947032 & 5.8 & 23.2 \\
TE & 207 & 27.91256 & 11.21229 & 8.8 & 58.7 \\
Patents & 196 & 89.9102 & 119.1979 & 2.66 & 686.64 \\
$N$ total & 209 & & & & \\
\hline
\end{tabular}

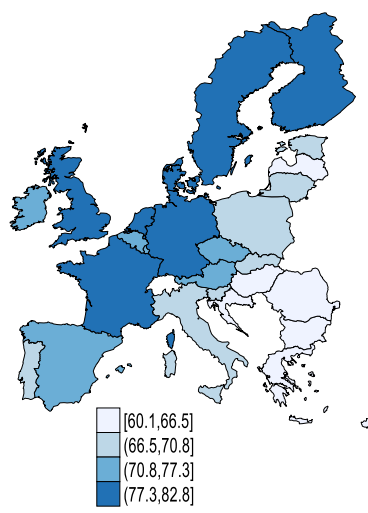

(a) GCI

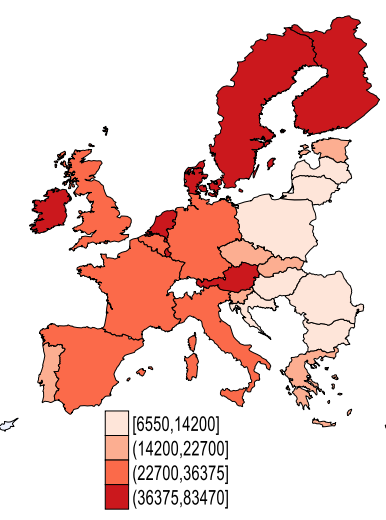

(b) GDP_cap

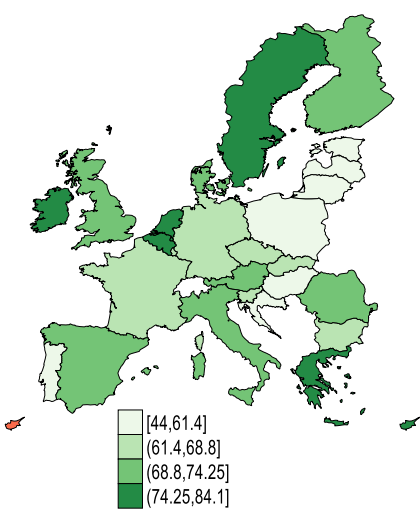

(c) PGH

Fig. 1 Outlook on a GCI, b GDP per capita and c PGH levels in 2018 across the European Union. Source: Authors' contribution in Stata 16

countries. The highest levels of competitiveness were achieved particularly by the Nordic States, Germany, France and the UK (since the dataset is compiled until 2018, at that time UK was still officially part of the EU). Moreover, CEECs (new EU Member States) have also registered the lowest GDP per capita levels (Fig. 1b), significantly lagged behind the Nordic States, Netherlands, Austria and Ireland. In terms of individuals perceived health, positive levels are also registered by EU-15 countries, while among the CEECs, Romania and Bulgaria tend to detach with higher values compared to the other considered economies.

On the other hand, when we have assessed the time trend and evolution of indicators for the 11 CEECs countries considered within our analysis during the entire 2000-2018 period, we have noticed that most of them have reached important increases in GDP per capita levels, particularly the Czech Republic, Slovak Republic, Slovenia and the Baltic States, while Romania and Bulgaria remain with the lowest levels of GDP per capita within the EU (Fig. 2). Despite this counter-performance, both countries have the highest levels of individuals' good and very good perceived health and have made significant efforts to improve country competitiveness, thus registering a positive trend of GCI throughout this lapse of time. Nevertheless, the competitiveness levels are very modest for CEECs 

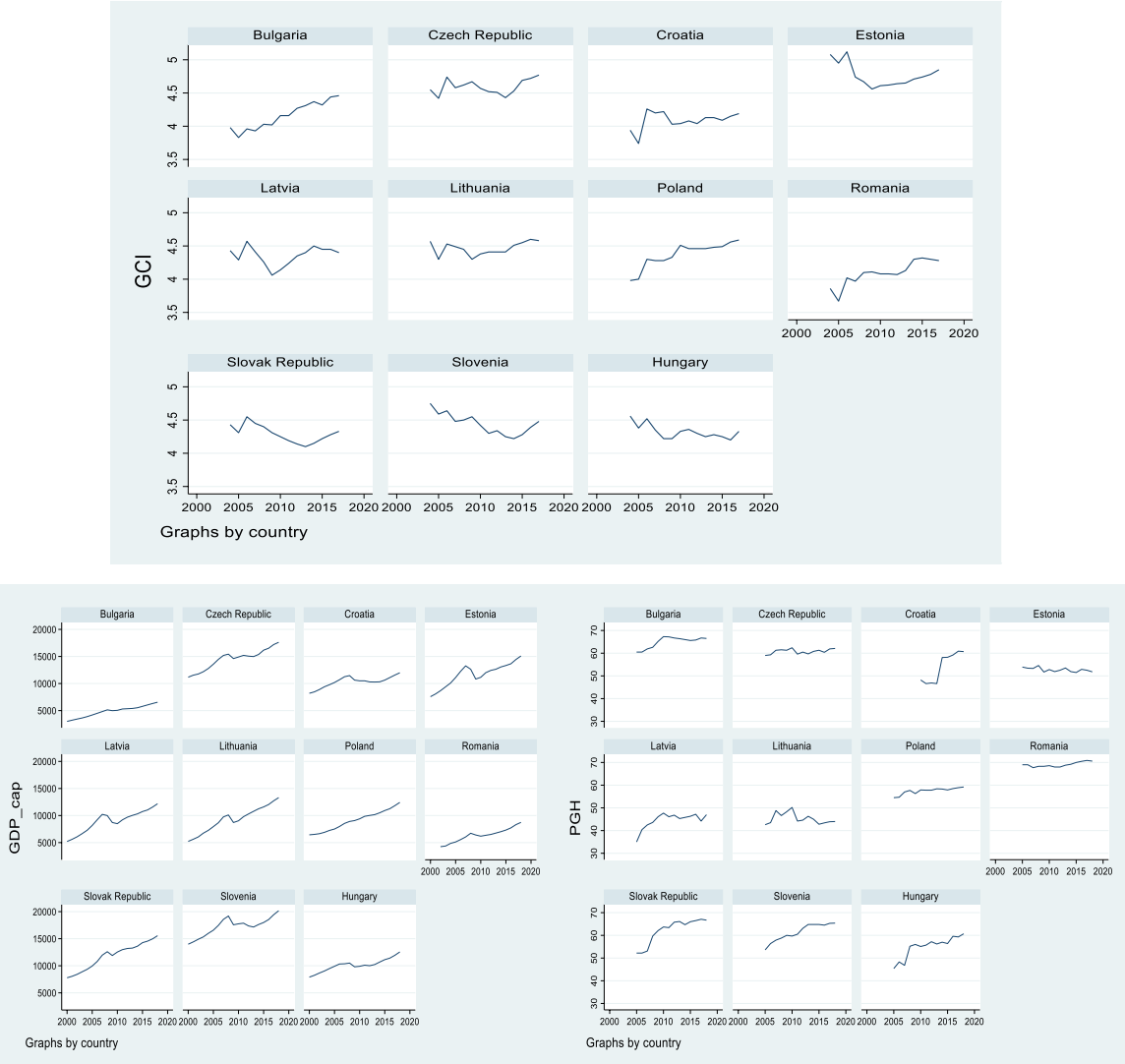

Fig. 2 Trends of main indicators during 2000-2018, graphs by each EU-11 countries considered within the panel. Source: Authors' contribution in Stata 16

countries and this issue continues to be in the center of debates for policy-makers and practitioners and raise serious concern about the groundings and drivers of competitiveness for these countries and the further interlinkages with sustainable economic development.

Taking a first look at the data, the correlation matrix (Table 2 and Fig. 3) between all selected indicators (that have been initially processed through the logarithm procedure to cope with non-stationarity and to provide common groundings for comparison due to their different measurement units) entail a strong correlation between the competitiveness levels of CEECs and the basic coordinates of the knowledge economy, namely education, research and development (captured through lifelong learning - LLL, tertiary education$\mathrm{TE}$ and general expenditure on research and development-GERD). At the same time, individuals perceived good health and well-being (PGH) is strongly correlated with the level of tertiary education (TE), but also with the innovation activities proxied through the number of patents (Patents). GDP per capita is also strongly correlated with the research and development activities and financial support (GERD), employment in technology and knowledge-intensive sectors at the national level (HTech) and lifelong learning (LLL), thus reinforcing the milestone importance of an effective innovative and educational system for increased competitiveness, economic welfare and sustainable development of CEECs. 
Table 2 Correlation matrix of selected indicators deployed in the empirical analysis, EU-CEECs-11, 20002018. Source: Authors' contribution in Stata 16

\begin{tabular}{|c|c|c|c|c|c|c|c|c|}
\hline & GCI & GDP_cap & PGH & GERD & HTech & LLL & $\mathrm{TE}$ & Patents \\
\hline GCI & 1.0000 & & & & & & & \\
\hline GDP_cap & 0.4820 & 1.0000 & & & & & & \\
\hline PGH & -0.2286 & -0.1532 & 1.0000 & & & & & \\
\hline GERD & 0.5203 & 0.7467 & -0.0265 & 1.0000 & & & & \\
\hline HTech & 0.3078 & 0.6009 & 0.2367 & 0.7020 & 1.0000 & & & \\
\hline LLL & 0.5866 & 0.7581 & -0.3400 & 0.7210 & 0.3977 & 1.0000 & & \\
\hline TE & 0.4768 & 0.2654 & -0.5109 & 0.3663 & 0.0776 & 0.4007 & 1.0000 & \\
\hline Patents & 0.2984 & 0.3367 & 0.3504 & 0.3878 & 0.3857 & 0.1798 & -0.0341 & 1.0000 \\
\hline
\end{tabular}

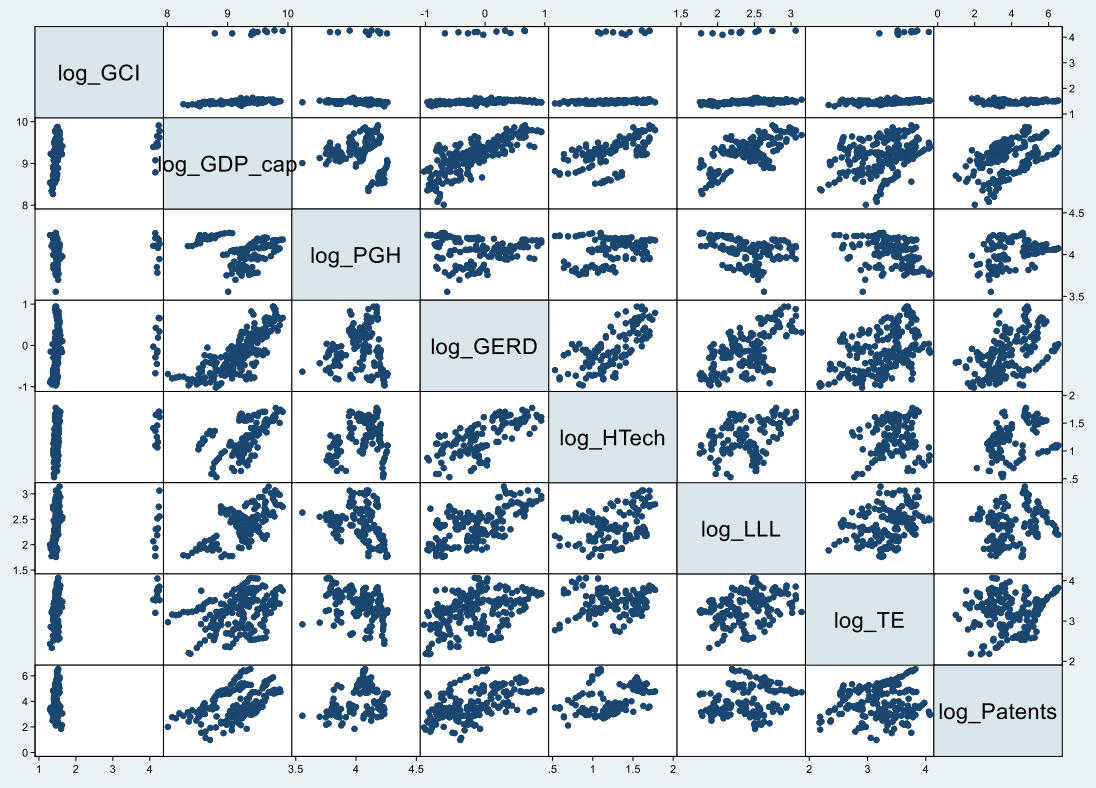

Fig. 3 Correlation graph matrix of selected indicators, EU-CEECs 11 countries, 2000-2018. Source: Authors' contribution in Stata 16

On these lines, we can attest that an accurate analysis of the role played by knowledge-driven competitiveness for economic convergence, sustainable development and individual well-being, particularly in the case of the CEECs that face low levels of both competitiveness and economic welfare, needs to be comprehensive, all-embracing, in order to provide a solid basis for accurate and tailored policies and strategies. Hence, our analysis is based on modern and complex econometric techniques in order to capture the main drivers of competitiveness in the knowledge economy, and their further consequences on income levels (GDP per capita as a proxy for economic welfare) and 
individuals' health and well-being, as well as the direct, indirect and total interlinkages between all considered coordinates.

\subsection{Methodology}

Our research endeavor follows the waterfall approach, the research being planned in phases and the outcome of one phase acts as an input for the next phase sequentially. Hence, in the initial phase of our empirical analysis, the variables were subject to the application of logarithm in order to cope with non-stationarity and to provide common groundings for comparison due to the different measurement units of considered indicators. Then, the methodology consisted of three econometric procedures, namely macroeconometric models, structural equation modeling (SEM) and network analysis through Gaussian Graphical Models (GGMs), since for a "sensitivity analysis, it is recommended to apply and compare various methods and/or various instruments ... each trying to discard the other's limits, so that the final estimations are accurate, robust, and correctly interpreted" (Noja et al. 2018: 7).

Macroeconometric models are designed as panel-data multifactorial regressions, being configured to test the first two research hypotheses $\left(\mathrm{H}_{1}\right.$ and $\left.\mathrm{H}_{2}\right)$ as in Eqs. (1-3):

For $\mathrm{H}_{1}$ :

$$
\begin{aligned}
\log \_G C I= & \delta+\beta_{1} \log \_G E R D+\beta_{2} \log \_H T e c h+\beta_{3} \log \_L L L \\
& +\beta_{4} \log _{-} T E+\beta_{5} \log \_ \text {Patents }+\theta_{i}+\lambda_{t}+\varepsilon
\end{aligned}
$$

For $\mathrm{H}_{2}$ :

$$
\begin{aligned}
& \text { log_GDP_cap }=\delta+\beta_{1} \log \_G C I+\beta_{2} \log \_G E R D+\beta_{3} \log \_H T e c h+\beta_{4} \log \_L L L \\
& +\beta_{5} \log \_T E+\beta_{6} \log \_ \text {Patents }+\theta_{i}+\lambda_{t}+\varepsilon \\
& \text { log_PGH }=\delta+\beta_{1} l o g \_G D P \_c a p+\beta_{2} \log \_G C I+\beta_{3} \log \_G E R D+\beta_{4} \log \_H T e c h \\
& +\beta_{5} \log \_L L L+\beta_{6} \log \_T E+\beta_{7} \log \_ \text {Patents }+\theta_{i}+\lambda_{t}+\varepsilon
\end{aligned}
$$

where " $\delta$ and $\beta$ are the parameters that need to be estimated, $\varepsilon$ is a stochastic element, and $\theta_{i}$ and $\lambda_{t}$ are variables that capture the country and time effects" (Cristea et al. 2020: 10).

In order to ensure robustness and validity of the results obtained, and to avoid the problem of perfect multicollinearity inherent in multiple regressions, the multifactorial models are processed through four estimation methods and associated procedures going beyond the classical OLS, namely robust regression (RREG), correlated panels corrected standard errors (PCSE), two stage least squares-IV estimators (2SLS-IV) and generalized method of moments (Arellano-Bond dynamic GMM).

Structural Equation Modelling (SEM) is further used in the empirical analysis since it represents an "integrative procedure that appraises overall interlinkages among considered variables, direct, indirect, and total" (Cristea et al. 2020: 9). SEM models are grounded on the universal representation entailed by Eq. 4 (Noja et al. 2018: 8). 


$$
\left\{\begin{array}{l}
b_{11} y_{2 t}+\cdots+b_{1 m} y_{m t}+c_{11} x_{1 t}+\cdots+c_{1 n} x_{n t}=\varepsilon_{1 t} \\
b_{21} y_{2 t}+\cdots+b_{2 m} y_{m t}+c_{21} x_{1 t}+\cdots+c_{2 n} x_{n t}=\varepsilon_{2 t} \\
\cdots \cdots \\
b_{m 1} y_{m t}+\cdots+b_{m m} y_{m t}+c_{m 1} x_{n t}+\cdots+c_{m n} x_{n t}=\varepsilon_{m t}
\end{array}\right.
$$

"where $t$ is the number of observed time periods, $b_{i j}$ represents the $y_{i j}$ endogenous variable's parameters, $c_{i j}$ are the $x_{i j}$ exogenous variable's parameters, $i=1, \ldots, m, j=1, \ldots, n$, and $\varepsilon$ comprises the error term (residuals)" (Noja et al. 2018: 8).

SEM represent modern techniques of data analysis with major practical advantages in social sciences since they offer meaningful and more valid results where alternative methods fail to do so. In our research, SEM are designed to provide a double-check of the results obtained through the multifactorial models, since they capture the direct, indirect and total linkages between the shaping factors of competitiveness in the knowledge economy, their outputs, and further impact on economic welfare and individual health and well-being (direct, indirect, bidirectional and mediated paths). Therefore, different from the multifactorial regression models, the structural equation models designed allowed us to test $\mathrm{H}_{3}$ in a unitary approach — comprehensive framework — single setting. Moreover, the SEM models are processed through a different estimation method (namely, the Maximum Likelihood Estimator-MLE) compared to the ones used for the macroeconometric models, thus ensuring robustness and accuracy of the estimations and additional support for the conclusions drawn and the entire research endeavor.

The general configuration of the SEM models designed to accomplish the research objective and to test $\mathrm{H}_{3}$ research hypothesis in a comprehensive framework on various scenarios $(\mathrm{a}, \mathrm{b}, \mathrm{c})$ that encompass the direct, indirect, bidirectional, mediated paths and total interlinkages between knowledge-based competitiveness, economic welfare and individual health and well-being (as a benchmark for sustainable development), is presented in Fig. 4.

The methodological endeavor is complemented in the final stage of our research with the network analysis based on a Gaussian Graphical Model (GGM) estimated through two procedures, namely Extended Bayesian Information Criteria (Ebic in conjunction with graphical lasso) and Partial Correlations (Pcor). These models are of significant interest in modern applications and provide in-depth cross-validation through the performance of the criterion on simulated data (Foygel and Drton 2010).

\section{Results and discussion}

\subsection{Results of macroeconometric models}

The first multifactorial model described in Eq. (1) is deployed to test the first work hypothesis $\left(\mathrm{H}_{1}\right)$ aiming to assess the shaping factors of CEECs competitiveness grounded on the fundamentals of the knowledge economy. The results obtained after processing the macroeconometric model through four different estimation procedures (RREG, PCSE, 2SLS-IV and GMM) are consistent in sign in the presence of statistical significance being synthesized in Table 3.

By analysis the first set of results, we note that education is essential and the most important driver of CEECs' competitiveness. In this regard, both lifelong learning captured 


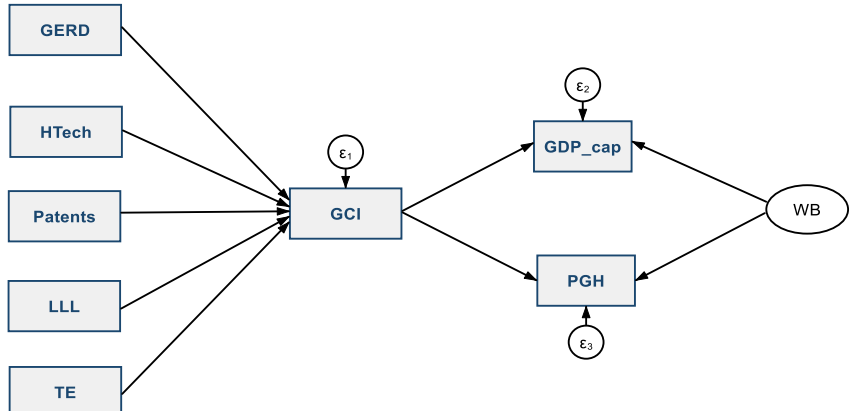

(a)

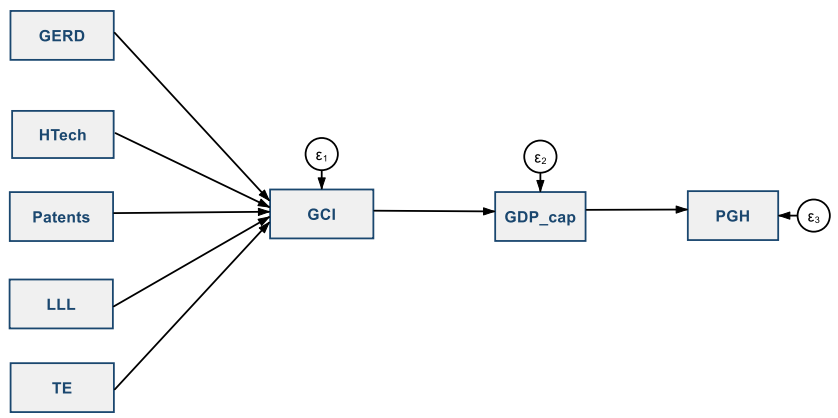

(b)
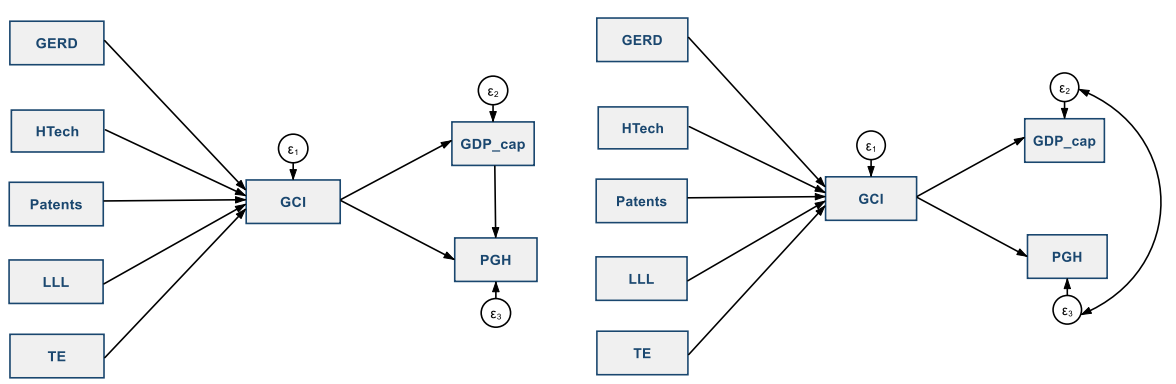

(c)

Fig. 4 General configuration of the SEM models designed to test $\mathrm{H}_{3}$ in a comprehensive approach-single setting, on various scenarios (a-c), EU-CEECs-11, 2000-2018. Source: Authors' own design in Stata 16

through the degree of participation in education and training of people aged between 18 and 74 years and the tertiary educational attainment level of young people aged 30-34 years are uttermost credentials that contribute to the significant increase of CEECs' competitiveness (the estimated coefficients associated with $L L L$ and $T E$ variables are positive for all four estimation methods and highly significant from a statistical point of view at the $0.1 \%$ threshold). At the same time, the innovation activity, captured in our models through the number of patent applications, represents also an important driver of competitiveness for the 11 CEECs considered within the panel (positive estimated coefficients, statistically significant). At the same time, the competitiveness levels reached in previous years (captured 
Table 3 Results of multifactorial regression models processed to assess the drivers of competitiveness, EU-CEECs-11, 2000-2018. Source: Authors' contribution in Stata 16

\begin{tabular}{|c|c|c|c|c|}
\hline & (1) & (2) & (3) & (4) \\
\hline & log_GCI & log_GCI & log_GCI & log_GCI \\
\hline & RREG & PCSE & 2SLS-IV & GMM \\
\hline log_GERD & $\begin{array}{l}0.00136 \\
(0.0137)\end{array}$ & $\begin{array}{l}-0.000622 \\
(0.00876)\end{array}$ & $\begin{array}{l}-0.000622 \\
(0.0130)\end{array}$ & $\begin{array}{l}-0.0156 \\
(0.0103)\end{array}$ \\
\hline log_HTech & $\begin{array}{l}0.00574 \\
(0.0162)\end{array}$ & $\begin{array}{l}0.00596 \\
(0.0110)\end{array}$ & $\begin{array}{l}0.00596 \\
(0.0154)\end{array}$ & $\begin{array}{l}0.0262 \\
(0.0188)\end{array}$ \\
\hline log_LLL & $\begin{array}{l}0.0531 * * * \\
(0.0153)\end{array}$ & $\begin{array}{l}0.0547 * * * \\
(0.0119)\end{array}$ & $\begin{array}{l}0.0547 * * * \\
(0.0145)\end{array}$ & $\begin{array}{l}0.0279 \\
(0.0194)\end{array}$ \\
\hline log_TE & $\begin{array}{l}0.0545 * * * \\
(0.0128)\end{array}$ & $\begin{array}{l}0.0483 * * * \\
(0.0132)\end{array}$ & $\begin{array}{l}0.0483 * * * \\
(0.0121)\end{array}$ & $\begin{array}{l}0.0234 \\
(0.0156)\end{array}$ \\
\hline log_Patents & $\begin{array}{l}0.00897 * \\
(0.00346)\end{array}$ & $\begin{array}{l}0.00919 * * * \\
(0.00194)\end{array}$ & $\begin{array}{l}0.00919 * * \\
(0.00328)\end{array}$ & $\begin{array}{l}0.00636 \\
(0.00611)\end{array}$ \\
\hline L.log_GCI & & & & $\begin{array}{l}0.546^{* * * *} \\
(0.0863)\end{array}$ \\
\hline _cons & $\begin{array}{l}1.112 * * * \\
(0.0634)\end{array}$ & $\begin{array}{l}1.128^{* * * *} \\
(0.0417)\end{array}$ & $\begin{array}{l}1.128 * * * \\
(0.0601)\end{array}$ & $\begin{array}{l}0.595^{* * * *} * \\
(0.155)\end{array}$ \\
\hline$N$ & 108 & 108 & 108 & 95 \\
\hline$R^{2}$ & 0.475 & 0.478 & 0.478 & \\
\hline
\end{tabular}

Standard errors in parentheses, ${ }^{*} p<0.05$; ${ }^{*} p<<0.01 ; * * * p<0.001$

in our model only in the case of Arellano Bond dynamic GMM-column 4 in Table 3) are decisive in positively shaping current competitiveness levels in the same framework of basic credentials of the knowledge economy (positive coefficient of 0.546 , highly significant from a statistical point of view at the $0.1 \%$ threshold). At the same time, increased levels of employment in technology and knowledge-intensive sectors in CEECs (HTech) have positive effects on these countries' competitiveness. On the other hand, the low levels of financial support granted to research and development activities (GERD) induce negative consequences on CEECs competitiveness leading to counter performances (negative estimated coefficients for three estimation procedures, even though with a lower degree of statistical significance). Hence, the first research hypothesis $H_{1}$ : CEECs competitiveness is positively driven and enhanced by the knowledge economy fundamentals, namely education, research and development and innovation is partially confirmed.

On these lines, we have further applied the other multifactorial models designed to test the second research hypotheses $\left(\mathrm{H}_{2}\right)$ and to see how these cumulated shaping factors, together with an increased competitiveness are jointly significant in directly influencing the economic welfare (measured through GDP_cap) (Table 4) and further the individuals' perceived health and well-being (captured through $P G H$ ) (Table 5) of CEECs. The results obtained are synthesized in Tables 4 and 5 .

Main results of the second set of macroeconometric models (Table 4) designed to assess the direct impact of competitiveness and other fundamental credentials on economic welfare (captured through GDP_cap) entail that all these coordinates are essential in jointly inducing an upward trend in GDP per capita. Furthermore, the $\mathrm{R}^{2}$ values reveal that around $68 \%$ of the variations in GDP per capita levels can be explained by the variations in competitiveness, education, research and development and innovation. Our results bring additional empirical evidence to attest that increases in knowledge-driven competitiveness lead to significant increases in GDP per capita levels in CEECs, hence being a major 
Table 4 Results of multifactorial regression models processed to assess the impact of competitiveness and its main drivers on economic welfare (GDP per capita), EU-CEECs-11, 2000-2018. Source: Authors' contribution in Stata 16

\begin{tabular}{|c|c|c|c|c|}
\hline & (1) & (2) & (3) & (4) \\
\hline & log_GDP_cap & log_GDP_cap & log_GDP_cap & log_GDP_cap \\
\hline & RREG & PCSE & 2SLS-IV & GMM \\
\hline log_GCI & $\begin{array}{l}0.00785 \\
(0.604)\end{array}$ & $\begin{array}{l}0.0967 \\
(0.687)\end{array}$ & $\begin{array}{l}0.0967 \\
(0.570)\end{array}$ & $\begin{array}{l}0.891 * * * \\
(0.182)\end{array}$ \\
\hline log_GERD & $\begin{array}{l}0.163 * \\
(0.0791)\end{array}$ & $\begin{array}{l}0.156^{* * * *} \\
(0.0469)\end{array}$ & $\begin{array}{l}0.156^{*} \\
(0.0747)\end{array}$ & $\begin{array}{l}0.0390 \\
(0.0223)\end{array}$ \\
\hline log_HTech & $\begin{array}{l}0.226^{*} \\
(0.0938)\end{array}$ & $\begin{array}{l}0.226^{* * * *} \\
(0.0569)\end{array}$ & $\begin{array}{l}0.226^{*} \\
(0.0885)\end{array}$ & $\begin{array}{l}0.0878 * \\
(0.0405)\end{array}$ \\
\hline log_LLL & $\begin{array}{l}0.482 * * * \\
(0.0946)\end{array}$ & $\begin{array}{l}0.519 * * * \\
(0.106)\end{array}$ & $\begin{array}{l}0.519 * * * \\
(0.0892)\end{array}$ & $\begin{array}{l}0.0664 \\
(0.0382)\end{array}$ \\
\hline log_TE & $\begin{array}{l}-0.0603 \\
(0.0795)\end{array}$ & $\begin{array}{l}-0.0617 \\
(0.0854)\end{array}$ & $\begin{array}{l}-0.0617 \\
(0.0750)\end{array}$ & $\begin{array}{l}-0.0755^{*} \\
(0.0322)\end{array}$ \\
\hline log_Patents & $\begin{array}{l}0.0154 \\
(0.0208)\end{array}$ & $\begin{array}{l}0.0199 \\
(0.0117)\end{array}$ & $\begin{array}{l}0.0199 \\
(0.0196)\end{array}$ & $\begin{array}{l}0.00937 \\
(0.0126)\end{array}$ \\
\hline L.log_GDP_cap & & & & $\begin{array}{l}0.611 * * * \\
(0.0625)\end{array}$ \\
\hline _cons & $\begin{array}{l}7.995 * * * \\
(0.774)\end{array}$ & $\begin{array}{l}8.043 * * * \\
(0.849)\end{array}$ & $\begin{array}{l}8.043 * * * \\
(0.731)\end{array}$ & $\begin{array}{l}1.742 * * \\
(0.536)\end{array}$ \\
\hline$N$ & 108 & 108 & 108 & 95 \\
\hline$R^{2}$ & 0.648 & 0.686 & 0.686 & - \\
\hline
\end{tabular}

Standard errors in parentheses, $* p<0.05 ; * * p<0.01 ; * * * p<0.001$

determinant of economic development for these countries (positive estimated coefficients associated with GCI variable throughout all four estimation procedures, e.g. 0.891 in model 4 GMM, highly significant from a statistical point of view, but also with the one-lag value of $G C I$ of 0.611 , along with positive estimated coefficients for all the other explanatory variables considered, except for $T E$ ). Lifelong learning represents another crucial factor for economic growth (positive estimated coefficients associated with the $L L L$ variable, statistically significant at the $0.1 \%$ threshold), as well as the significant employment increases in technology and knowledge-intensive sectors across the CEECs. Among the considered exogenous variables, only $T E$ accounts a negative impact on GDP per capita levels, thus entailing that the tertiary educational programs of Central and Eastern European countries need to be reconfigured in order to match the current economic and labor market needs in a globalized digital economy and to provide the adequate knowledge for employability, upskilling, as key elements for achieving a sustainable economic development.

Our results are in line with the study of Dima et al. (2018), that have also highlighted the crucial role of innovation and education as drivers of EU competitiveness. Likewise, Guellec and Van Pottelsberghe de la Potterie (2001) examined the impact of R\&D on multifactor productivity growth on the long-run and pointed out that there is a strong and positive effect of the business, public and foreign R\&D on productivity growth. Main findings of Menbere and Hekelova (2016) also point out that the countries with an advanced level of tertiary education and training tend to achieve a higher level of the GCI indicator compared to countries with lower levels of education and innovation performance. Contrary to 
Table 5 Results of multifactorial regression models processed to assess the impact of competitiveness and economic welfare (GDP per capita) on individuals' perceived health and well-being, EU-CEECs-11, 2000-2018. Source: Authors' contribution in Stata 16

\begin{tabular}{|c|c|c|c|c|}
\hline & (1) & (2) & (3) & (4) \\
\hline & log_PGH & log_PGH & log_PGH & log_PGH \\
\hline & RREG & PCSE & 2SLS-IV & GMM \\
\hline log_GDP_cap & $\begin{array}{l}-0.0851 \\
(0.0546)\end{array}$ & $\begin{array}{l}-0.0904 * * \\
(0.0315)\end{array}$ & $\begin{array}{l}-0.0904 \\
(0.0535)\end{array}$ & $\begin{array}{l}-0.0265 \\
(0.0720)\end{array}$ \\
\hline log_GCI & $\begin{array}{l}-0.299 \\
(0.309)\end{array}$ & $\begin{array}{l}-0.0932 \\
(0.216)\end{array}$ & $\begin{array}{l}-0.0932 \\
(0.302)\end{array}$ & $\begin{array}{l}-0.112 \\
(0.231)\end{array}$ \\
\hline log_GERD & $\begin{array}{l}0.0894 * \\
(0.0421)\end{array}$ & $\begin{array}{l}0.0697 * * \\
(0.0223)\end{array}$ & $\begin{array}{l}0.0697 \\
(0.0412)\end{array}$ & $\begin{array}{l}-0.0441 \\
(0.0262)\end{array}$ \\
\hline log_HTech & $\begin{array}{l}0.116^{*} \\
(0.0505)\end{array}$ & $\begin{array}{l}0.115^{* * * *} \\
(0.0204)\end{array}$ & $\begin{array}{l}0.115^{*} \\
(0.0494)\end{array}$ & $\begin{array}{l}0.00596 \\
(0.0464)\end{array}$ \\
\hline log_LLL & $\begin{array}{l}-0.161 * * \\
(0.0570)\end{array}$ & $\begin{array}{l}-0.136 * * \\
(0.0488)\end{array}$ & $\begin{array}{l}-0.136^{*} \\
(0.0558)\end{array}$ & $\begin{array}{l}-0.0857 \\
(0.0511)\end{array}$ \\
\hline log_TE & $\begin{array}{l}-0.214^{* * *} \\
(0.0415)\end{array}$ & $\begin{array}{l}-0.192 * * * \\
(0.0308)\end{array}$ & $\begin{array}{l}-0.192 * * * \\
(0.0407)\end{array}$ & $\begin{array}{l}-0.0732 \\
(0.0414)\end{array}$ \\
\hline log_Patents & $\begin{array}{l}0.0340 * * \\
(0.0108)\end{array}$ & $\begin{array}{l}0.0360 * * * \\
(0.00496)\end{array}$ & $\begin{array}{l}0.0360 * * * \\
(0.0105)\end{array}$ & $\begin{array}{l}0.0270 \\
(0.0142)\end{array}$ \\
\hline L.log_PGH & & & & $\begin{array}{l}0.542 * * * \\
(0.0789)\end{array}$ \\
\hline _cons & $\begin{array}{l}6.136 * * * \\
(0.585)\end{array}$ & $\begin{array}{l}5.727 * * * \\
(0.323)\end{array}$ & $\begin{array}{l}5.727 * * * \\
(0.573)\end{array}$ & $\begin{array}{l}2.327 * * * \\
(0.691)\end{array}$ \\
\hline$N$ & 106 & 106 & 106 & 92 \\
\hline$R^{2}$ & 0.550 & 0.512 & 0.512 & - \\
\hline
\end{tabular}

Standard errors in parentheses, $* p<0.05 ; * * p<0.01 ; * * * p<0.001$

these findings, we can attest that the tertiary educational programs of Central and Eastern European countries need to be tailored to the needs of and opportunities offered by the digital economy.

The final set of macroeconometric models further link knowledge driven-competitiveness and economic welfare to individuals' health and well-being (Table 5). In this setting, different from other approaches that have generally linked competitiveness only with economic growth, our approach goes further and assesses the way in which individuals perceive the national competitiveness and welfare increases as being in their benefit.

Main results bring to the fore that there is evidence to attest a negative cumulated impact on all knowledge-driven competitiveness credentials and GDP per capita (income levels) improvements on perceived health and well-being $(P G H)$ of CEECs citizens (negative estimated coefficients associated with GCI, GDP_cap, LLL, TE, statistically significant). The only variables with favorable consequences are Patents and HTech, while in the case of GERD the results are controversial (slight change in sign throughout different estimation procedures). These results are extremely important since they entail that even though competitiveness increases under the positive influence of key drivers in the knowledge economy and this leads to economic welfare measured through GDP per capita upwards, the final positive outcome on individuals' health and well-being is not reached in current policy framework. Therefore, there is a keen need to redesign a new set of policies, strategies and accurate measures tailored 
to CEECs economic systems in order to enable competitiveness increases in the benefit of individuals.

Several measures in this respect could encompass the increase of investment in the health systems, the participation of CEE economies in global value chains, promoting social inclusiveness, an upgrade of the legal system, a greater affordability of the financial environment, which will support innovative companies and the reconfiguration of the tertiary education in both quality and quantity in order to meet the labor market needs.

Therefore, the second research hypothesis $\mathrm{H}_{2}$ : There are significant positive implications of CEECs knowledge-driven competitiveness on economic welfare and individuals' well-being is partially confirmed.

\subsection{Results of structural equation models (SEM)}

Fully consistent with the stated research objectives, we have complemented the methodological endeavor with several structural equation models (SEM) designed to test $\mathrm{H}_{3}$ in a comprehensive framework on various scenarios, as presented in Fig. 4, being processed through the maximum likelihood procedure (Maximum Likelihood EstimatorMLE). The results obtained are synthesized in Fig. 5. We have applied a series of validation tests (like Alpha Cronbach, Goodness of fit tests, Wald tests for each equation) and the results obtained (detailed in the Appendix, Tables 6, 7, 8) entail the reliability of the scale and accuracy of the estimations.

SEM models allowed us to test the research hypotheses by simultaneously assessing the complex patterns of relationships (direct, indirect, bidirectional, total) between all considered variables in a single setting. Hence, SEM results reconfirm previous estimations of macroeconometric models and highlight that the competitiveness of CEECs is positively driven and enhanced by the key credentials of the knowledge economy (positive and statistically significant estimated coefficients associated with GERD, HTech, Patents, LLL and TE variables in all four SEM models). Hence, $H_{1}$ is reconfirmed and fulfilled. At the same time, in a further complex setting, competitiveness increases under the impact of education, R\&D and innovation coordinates lead to significant upwards in GDP per capita levels (positive estimated coefficients associated with GDP_cap variable in all four SEM models, highly significant from a statistical point of view). However, the further linkages with individuals' perceived good health and well-being, when considered as a consequence of welfare increase following knowledge-driven competitiveness (Fig. 5b), or direct impact of competitiveness increases (Fig. 5a), entail a downsized outcome in terms of perceived general health (negative estimated coefficients associated with $P G H$ variable, which is a good predictor of people's future use of the healthcare system and mortality risk). Therefore, the second work hypothesis $\mathrm{H}_{2}$ : There are significant implications of CEECs knowledge-driven competitiveness on economic welfare and individuals' well-being is reconfirmed and fulfilled.

However, when we have allowed for a correlation between GDP_cap and PGH (bidirectional path as entailed in Fig. 5c), together with the cumulated effect of knowledge driven competitiveness enhancement, the final impact on $P G H$ was positive (estimated coefficient of 0.031 in Fig. 5c, even though with a lower degree of statistical significance). These results are extremely important for policy makers and practitioners since they provide new empirical evidence to entail that enhanced coordinated efforts are needed on multiple dimensions and intervention areas in order to ensure beneficial 


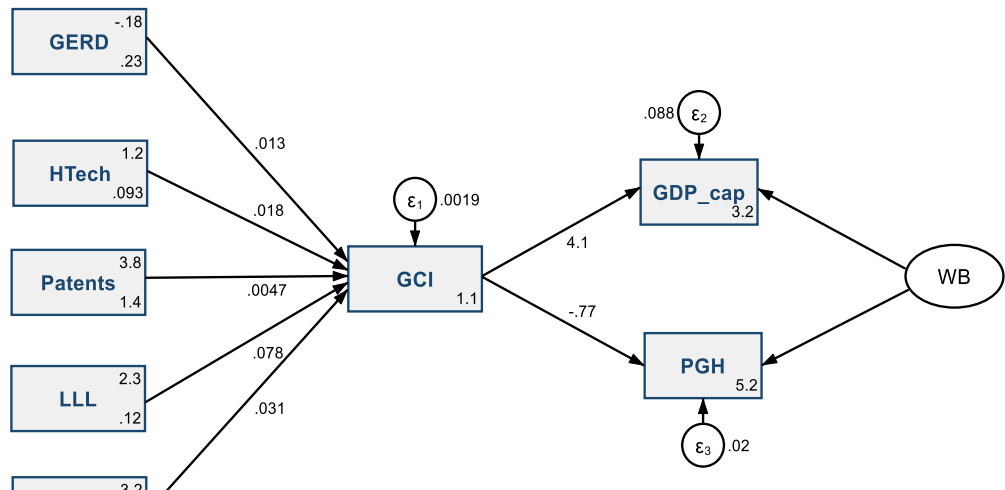

(a)
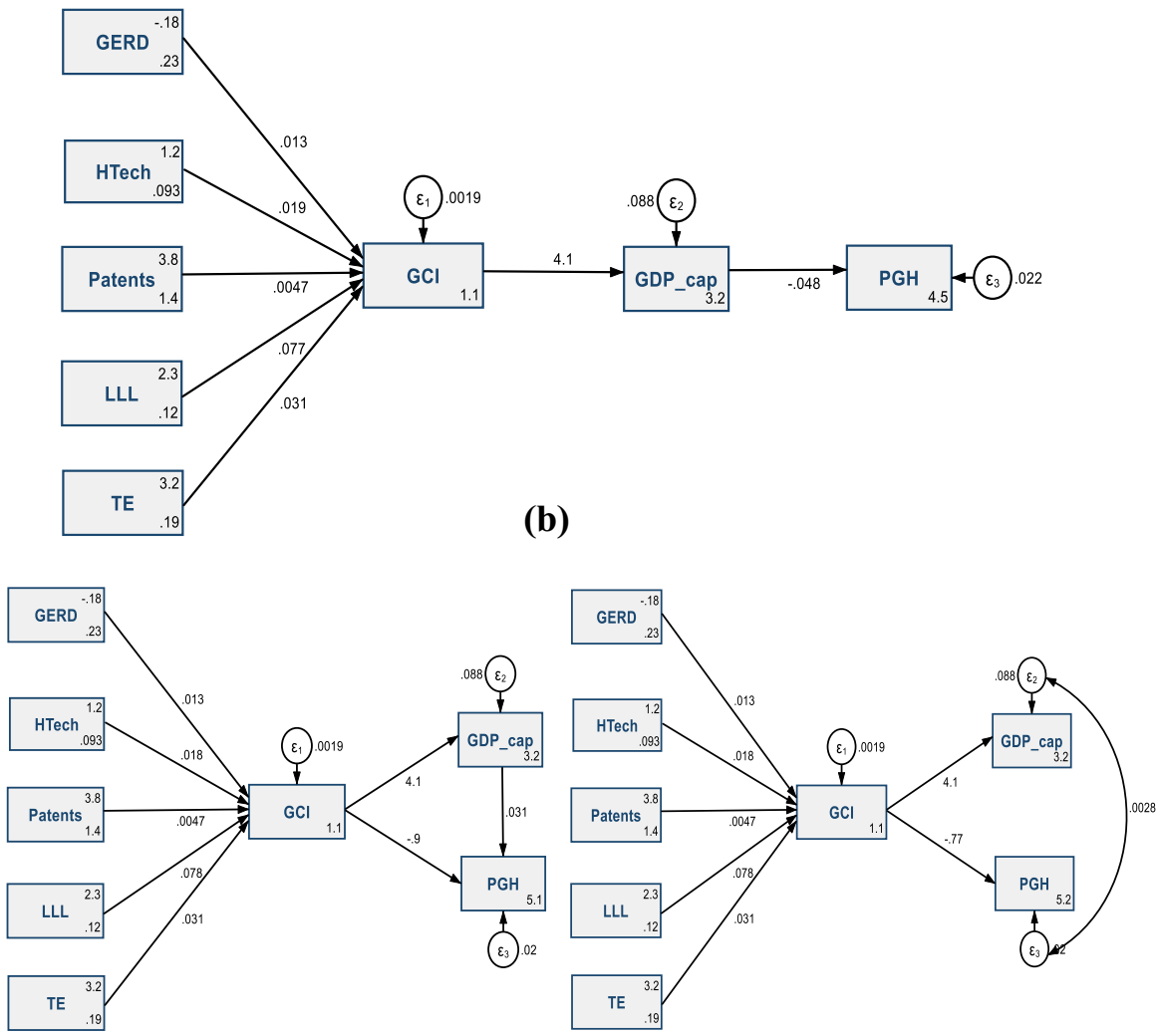

(c)

Fig. 5 Results of the SEM models designed to test $\mathrm{H}_{3}$ in a comprehensive approach-single setting, on various scenarios (a-c), EU-CEECs-11, 2000-2018. Source: Own contribution in Stata 16 
effects of competitiveness on sustainable economic development. In conclusion, the third research hypothesis $\mathrm{H}_{3}$ : There are substantial impacts and interlinkages between economic welfare driven by knowledge based competitiveness and individuals' perceived health and well-being (sustainable development) is fulfilled.

\subsection{Results of the network analysis-Gaussian Graphical Models (GGMs)}

In order to fully verify and validate the third research hypothesis $H_{3}$, we have also applied another modern technique used in social sciences, namely the network analysis which is based on a Gaussian Graphical Model estimated through two methods, respectively Extended Bayesian Information Criteria with graphical lasso (Fig. 6a) and Partial correlations (Fig. 6b).

In the pre-settled framework that we have designed following our general research objective and methodological endeavor, both GGMs have placed CEECs competitiveness in direct relation with tertiary education $(T E)$ and employment in technology and knowledge-intensive sectors (HTech), but also with the government financial support granted for research and development activities $(G E R D)$. Hence, these coordinates are essential for enhancing CEECs competitiveness, with benefit spillovers on sustainable economic development $\left(H_{3}\right.$ is reconfirmed and fulfilled $)$. Our results offer a sound basis for the development of new policies centered on these coordinates that have proved (from an empirical perspective) to induce a climb in competitiveness and economic welfare enlargement.

These results are consistent with the studies of Lapinskiene (2011) and Herciu and Ogrean (2015). The research of Lapinskiene (2011) underlined that the competitiveness level of the country's economy is strongly interconnected with the sustainability indicators. It has been demonstrated that for the developing countries, GDP growth should be maintained to increase the sustainability. The study of Herciu and Ogrean (2015: 556) underlined strong interrelations between "national wealth, national competitiveness and national intellectual capital, that lead to increased economic development".

In a different perspective, the main results of the study of Simionescu et al. (2017) have shown that the FDI generated economic growth in all countries, except Romania and Slovak Republic, but a higher economic growth attracted more foreign investors. Contrary to these findings, we can attest that knowledge economies contribute to the economic development and the well-being of citizens through its crucial drivers, namely lifelong learning, investments in IT, research and education.

\section{Conclusion}

This research was designed and applied to explore the decisive role of knowledge-driven competitiveness in enhancing economic welfare and sustainable development (individuals' health and well-being), with a particular focus on countries in Central and Eastern Europe, members of the European Union. Grounded on the critical analysis of the literature and driven by the notoriety of competitiveness in the knowledge economy setting, our research was set to test three work hypotheses, through three sets of econometric techniques (macroeconometric models, structural equation models and Gaussian graphical models).

The results obtained after performing the empirical analysis on each of the three research hypotheses and associated econometric methods applied reveal that CEECs 
Fig. 6 Gaussian graphical models (GGMs), EU-CEECs-11, 2000-2018: a Extended Bayesian Information Criteria with graphical lasso (EBIC lasso); b partial correlation (PCOR). Source: Authors' contribution in R
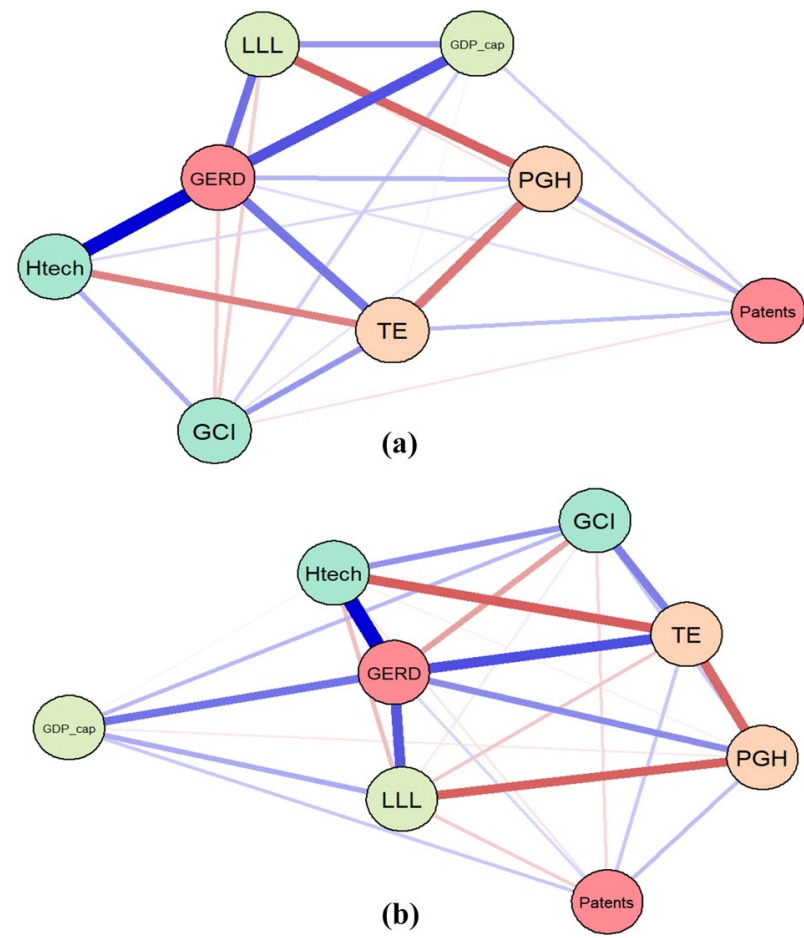

competitiveness is positively driven and enhanced by the key credentials of the knowledge economy [directly linked to tertiary education (TE) and employment in technology and knowledge-intensive sectors (HTech), but also with the government financial support granted for research and development activities (GERD)]. Our results are consistent with the findings of Dima et al. (2018), Sum and Jessop (2013) and Durazzi (2019) which have also have grasped significant interlinkages between competitiveness and the knowledgebased economy (with a keen focus on higher education, research and development and innovation). At the same time, in a further complex setting, competitiveness upturns as a result of education, $R \& D$ and innovation coordinates further lead to significant increases in GDP per capita levels (economic welfare), thus supporting sustainable economic development. These aspects were also outlined by Balkyte and Peleckis (2010), Lapinskiene (2011) and Feurer and Chaharbaghi (1994). Likewise, Guellec and Van Pottelsberghe de la Potterie (2001) pointed out that there is a strong and positive effect of the business, public and foreign R\&D on productivity growth, while the study of Herman (2018) underlined the significant effects of innovation and entrepreneurship on the national competitiveness of EU countries, sustaining that the high level of national competitiveness in some EU countries can be mainly explained by the high level of innovation performance and the high level of innovative and productive entrepreneurship.

However, our SEM results show that the further linkages with individuals' perceived good health and well-being, when considered as a consequence of welfare increase following knowledge-driven competitiveness or direct impact of competitiveness increases, lead to a downsized outcome in tersms of perceived general health (a good predictor of people's future use of the healthcare system and mortality risk and a benchmark for sustainable development). On the other hand, Lapinskiene (2011), Runiewicz-Wardyn (2018), 
Herciu and Ogrean (2015) and Huggins and Thompson (2017) have depicted that higher levels of competitiveness contribute to the overall increased levels of well-being, social development and sustainable development. Furthermore, by encompassing the perceptions of competitiveness in the context of sustainable development, Balkyte and Tvaronavičiene (2010) make use of the "sustainable competitiveness" notion and underline that competitiveness and economic growth are fundamental drivers for supporting living standards and wellbeing.

According to our results, strategic measures to enhance knowledge-driven competitiveness and sustainable economic development should have at their core tertiary educational attainment enhancement, lifelong learning programs, but also research and development support for innovation and employment in technology intensive sectors. These policies could include: (1) a reconfiguration of the tertiary educational programs of Central and Eastern European countries in order to match the current economic and labor market needs and to provide the adequate knowledge for employability, upskilling, as key elements for achieving a sustainable economic development; (2) the enhancement of lifelong learning approaches, as this configuration permits the appliance of a various learning options and new pedagogical approaches; (3) the minimize of the skill mismatches in the higher education system; (4) increase of FDI in the legal, health and educational systems, that will increase the efficiency and competitiveness of the CEE countries (Bibu et al. 2009); (5) an upgrade of the legal system, health and education; (6) the participation of CEE economies in global value chains, which will increase their productivity levels (Malgorzata 2018); (7) the creation and use of knowledge in the economic activities; (8) an increase of the R\&D expenditure that can significantly contribute to technical progress, competitiveness and individual well-being; (9) a greater affordability of the financial environment, which will support innovative companies (Pirtea et al. 2014; Özen, 2019a); (10) promoting social inclusiveness (Özen 2019b).

Several research limitations inherently constrain part of our findings and mainly consist on low availability of detailed data on a complex set of indicators that can better capture the amplitude and complexity of the competitiveness concept and, moreover, of economic welfare and well-being. Future research directions bring to the fore the fundamental importance of people's good health and well-being as a key strategic goal for sustainable development and target the development of new tailored operational models of competitiveness that keep sight also of the national economic features. At the same time, the intellectual capital is essential for an enhanced country competitiveness, hence we aim at considering the free movement of highly skilled labor within the European Union as another pillar of knowledge-driven competitiveness, particularly with respect to different ethnic groups (considering the works of Dinca and Luches 2018).

Author contributions GGN, CNJ, AB, and ILP designed the conceptualization of the paper, overall visualization, and prepared the original draft of the manuscript. GGN configured the methodology and applied the formal analysis, software; $\mathrm{CNJ}$ and $\mathrm{AB}$ prepared the dataset and reviewed the literature. ILP was in charge of writing - review and editing. AB covered the funding acquisition. All authors read and approved the final manuscript.

\section{Compliance with ethical standards}

Conflicts of interest The authors declare no conflicts of interest. 


\section{Appendix}

See Tables 6, 7, and 8 .

Table 6 SEM models' results for Cronbach's Alpha, EU-CEECs-11, 2000-2018. Source: Authors' contribution in Stata 16

\begin{tabular}{lllllll}
\hline Item & Obs & Sign & $\begin{array}{l}\text { Item-test cor- } \\
\text { relation }\end{array}$ & $\begin{array}{l}\text { Item-rest cor- } \\
\text { relation }\end{array}$ & $\begin{array}{l}\text { Average interitem } \\
\text { correlation }\end{array}$ & Alpha \\
\hline Log_GCI & 154 & + & 0.7521 & 0.6271 & 0.3440 & 0.7859 \\
Log_GDP_cap & 207 & + & 0.8688 & 0.7832 & 0.2996 & 0.7496 \\
Log_PGH & 149 & - & 0.3122 & 0.1017 & 0.4424 & 0.8474 \\
Log_HTech & 121 & + & 0.6511 & 0.4990 & 0.3655 & 0.8013 \\
Log_TE & 207 & + & 0.6017 & 0.4037 & 0.3834 & 0.8132 \\
Log_Patents & 196 & + & 0.5667 & 0.3914 & 0.4010 & 0.8241 \\
Log_LLL & 165 & + & 0.8184 & 0.7234 & 0.3239 & 0.7703 \\
Log_GERD & 207 & + & 0.8473 & 0.7691 & 0.3014 & 0.7512 \\
Total scale & & & & & & 0.8171 \\
\hline
\end{tabular}

Table 7 SEM models' results for Wald tests, EU-CEECs-11, 2000-2018. Source: Authors' contribution in Stata 16

\begin{tabular}{|c|c|c|c|c|c|c|c|c|c|c|c|c|}
\hline \multirow[t]{2}{*}{ Variables } & \multicolumn{3}{|c|}{ SEM 1} & \multicolumn{3}{|l|}{ SEM 2} & \multicolumn{3}{|l|}{ SEM 3} & \multicolumn{3}{|l|}{ SEM 4} \\
\hline & $\overline{\mathrm{Chi}^{2}}$ & $d f$ & $p$ value & $\overline{\mathrm{Chi}^{2}}$ & $d f$ & $p$ value & $\overline{\mathrm{Chi}^{2}}$ & $d f$ & $\overline{p \text { value }}$ & $\overline{\mathrm{Chi}^{2}}$ & $d f$ & $p$ value \\
\hline Log_GCI & 92.89 & 5 & 0.000 & 139.08 & 5 & 0.000 & 140.13 & 5 & 0.000 & 140.15 & 5 & 0.000 \\
\hline Log_GDP_cap & 32.08 & 1 & 0.000 & 133.30 & 1 & 0.000 & 131.62 & 1 & 0.000 & 131.60 & 1 & 0.000 \\
\hline Log_PGH & 5.85 & 1 & 0.015 & 6.99 & 1 & 0.016 & 12.50 & 2 & 0.001 & 11.79 & 1 & 0.000 \\
\hline
\end{tabular}

$\mathrm{H}_{0}$ : All coefficients excluding the intercepts are 0

We can therefore reject the null hypothesis $\left(\mathrm{H}_{0}\right)$ for each equation, with limitations on PGH

Table 8 SEM models' results for Goodness-of-fit tests, EU-CEECs-11, 2000-2018. Source: Authors' contribution in Stata 16

\begin{tabular}{lrrrr}
\hline & SEM 1 & SEM 2 & SEM 3 & SEM 4 \\
\hline Likelihood ratio & & & & \\
${\text { Model vs. saturated chi }{ }^{2} \text { _ms (15) }}$ & 169.162 & 244.789 & 234.816 & 234.816 \\
$\quad 0$ chi $^{2}$ & 0.000 & 0.000 & 0.000 & 0.000 \\
Baseline vs. saturated chi ${ }^{2}$ _bs (24) & 269.585 & 414.261 & 414.261 & 414.261 \\
$\quad p>$ chi $^{2}$ & 0.000 & 0.000 & 0.000 & 0.000 \\
Information criteria & & & & \\
AIC (Akaike's information criterion) & -49.561 & 525.887 & 517.914 & 517.914 \\
BIC (Bayesian information criterion) & 014.936 & 636.184 & 631.553 & 631.553 \\
Baseline comparison & & & & \\
CFI (comparative fit index) & 0.371 & 0.410 & 0.433 & 0.433 \\
$\quad$ TLI (Tucker-Lewis index) & -0.029 & 0.035 & -0.021 & -0.021 \\
Size of residuals & & & & \\
CD (coefficient of determination) & 0.467 & 0.489 & 0.490 & 0.490 \\
\hline
\end{tabular}




\section{References}

Balkite, A., Tvaronavičiene, M.: The inclusion of sustainable development dimension into the competitiveness theory. Bus. Manag. Educ. 18, 1-9 (2010)

Balkyte, A., Peleckis, K.: Mapping the future sustainable competitiveness resources: aspects of forests ownership. J. Bus. Econ. Manag. 11(4), 630-651 (2010)

Balkyte, A., Tvaronavičiene, M.: Perception of competitiveness in the context of sustainable development: facets of "sustainable competitiveness". J. Bus. Econ. Manag. 11(2), 341-365 (2010). https://doi. org/10.3846/jbem.2010.17

Bibu, N., Stefea, P., Sala, D.: External and internal environment influences on SME competitiveness from the Western Area of Romania. Megatrend Rev. 6(2), 41-52 (2009)

Bojan, K., Stanisic, T.: The influence of the knowledge economy development on competitiveness of Southeastern European Countries. Industrija 41(2), 151-167 (2013). https://doi.org/10.5937/industrija 41-4000

Bosworth, B., Collins, M.: The empirics of growth. Brook. Pap. Econ. Act. 2, 113-206 (2013). https://doi. org/10.1353/eca.2004.0002

Castells, M.: The rise of the network society. Blackwell Publishers, Hoboken (1996)

Cohen, D., Soto, M.: Growth and human capital. J. Econ. Growth 12, 51-76 (2007)

Cristea, M., Noja, G.G., Ștefea, P., Sala, A.L.: The impact of population aging and public health support on EU Labor Markets. Int. J. Environ. Res. Public Health 17, 1439 (2020)

Dima, A.M., Begu, L., Vasilescu, M.D., Maassen, M.A.: The relationship between the knowledge economy and global competitiveness in the European Union. Sustainability 10(6), 1706 (2018). https://doi. org/10.3390/su10061706

Dinca, M., Luches, D.: Work integration of the roma: between family and labor market. Sustainability 10(5), 1495 (2018)

Durazzi, N.: The political economy of high skills: higher education in knowledge-based labour markets. J. Eur. Public Policy 26(12), 1799-1817 (2019). https://doi.org/10.1080/13501763.2018.1551415

European Commission: Closing the Loop-An EU Action Plan for the Circular Economy. Communication from the Commission to the European Parliament, the Council, the European Economic and Social Committee and the Committee of the Regions 2015, COM/2015/0614 Final. https://www.eea.europ a.eu/policy-documents/com-2015-0614-final. Accessed 07 May 2020

European Commission: A Sustainable Bioeconomy for Europe: Strengthening the Connection Between Economy, Society and the Environment. Updated Bioeconomy Strategy. Brussels, Belgium (2018)

European Commission: Eurostat Database 2020. https://ec.europa.eu/eurostat/data/database. Accessed on 20 February 2020

Feurer, R., Chaharbaghi, K.: Defining competitiveness: a holistic approach. Manag. Decis. 32(2), 49-58 (1994). https://doi.org/10.1108/00251749410054819

Foygel, R., Drton, M.: Extended Bayesian information criteria for Gaussian Graphical Models. Adv. Neural. Inf. Process. Syst. 23, 2020-2028 (2010)

Geerken, T., Schmidt, J., Boonen, K., Christis, M., Merciai, S.: Assessment of the potential of a circular economy in open economies—case of Belgium. J. Clean. Prod. 227, 683-699 (2019). https://doi. org/10.1016/j.jclepro.2019.04.120

Georgescu-Roegen, N.: Energy and economic myths. South. Econ. J. 41(3), 347-381 (1975). https://doi. org/10.2307/1056148

Giampietro, M.: On the circular bioeconomy and decoupling: implications for sustainable growth. Ecol. Econ. 162, 143-156 (2019). https://doi.org/10.1016/j.ecolecon.2019.05.001

Gorji, E., Alipurian, M.: The knowledge economy \& the knowledge assessment methodology. Iran. Econ. Rev. 15(29), 43-72 (2011)

Guellec, D., Van Pottelsberghe de la Potterie, B.: R\&D 25- and Productivity Growth: Panel Data Analysis of 16 OECD Countries. STI Working Papers 3, Organisation for Economic Cooperation and Development, Paris (2001)

Hanushek, E., Kimko, D.: Schooling, labor force quality and the growth of nations. Am. Econ. Rev. 90(5), 1184-1208 (2000). https://doi.org/10.1257/aer.90.5.1184

Herciu, M., Ogrean, C.: Wealth, competitiveness, and intellectual capital-sources for economic development. Procedia Econ. Financ. 27, 556-566 (2015)

Herman, E.: Innovation and entrepreneurship for competitiveness in the EU: an empirical analysis. Proc. Int. Conf. Bus. Excell. 12(1), 425-435 (2018)

Huggins, R., Thompson, P.: Handbook of Regions and Competitiveness-Contemporary Theories and Perspectives on Economic Development. Edward Elgar Publishing, Cheltenham (2017) 
Jorgenson, D.W., Stiroh, K.: Raising the speed limit: U.S. economic growth in the information age. Brook. Pap. Econ. Act. 1, 125-211 (2000)

Kiselakova, D., Sofrankova, B., Cabinova, V., Onuferova, E., Soltesova, J.: The impact of R\&D expenditure on the development of global competitiveness within the CEE EU countries. J. Compet. 10(3), 34-50 (2018). https://doi.org/10.7441/joc.2018.03.03

Krstić, M., Krstić, B., Antonović, R.: The importance of science for improving competitiveness of national economy. Facta Univ. Ser. Econ. Organ. 16(1), 13-30 (2019). https://doi.org/10.22190/FUEO190101 $3 \mathrm{~K}$

Lapinskienè, G.: The analysis of the relationship between the sustainable development and competitiveness in the European countries. Intelektinè ekonomika 5(3), 434-444 (2011)

Lederman, M, Maloney, W.: R\&D Development. Policy Research Working Paper 3024, The World Bank (2003)

Malgorzata, R.-W.: Competitiveness and wellbeing of Central Eastern European economies in the last decade. Transformation, Integration and Globalization Economic Research (TIGER) 139, TIGER Working Paper Series (2018)

Marcu, N., Cristea, M., Meghisan, G.M., Dascalu, D., Nasta, L.N.: Impact of certain sectors of the economy on the chemical pollution of atmosphere in Romania. Rev. Chim. 67(6), 1195-1199 (2016)

Menbere, W., Hekelova, E.: Is the Global Competitiveness Index informative? CBU Int. Conf. Proc. 4, 132141 (2016). https://doi.org/10.12955/cbup.v4.754

Noja, G.G., Cristea, S.M., Yüksel, A., Pânzaru, C., Drăcea, R.M.: Migrants' role in enhancing the economic development of host countries: empirical evidence from Europe. Sustainability 10, 894 (2018). https:// doi.org/10.3390/su10030894

Oliner, S.D., Sichel, D.E.: The resurgence of growth in the late 1990s: is information technology the story? J. Econ. Perspect. 14(4), 3-22 (2000)

Özen, E.: Coping with the exceptional economic problems in Turkey: a field survey on SMEs. Timis. J. Econ. Bus. 12(2), 109-126 (2019a)

Özen, E.: The concept of trust in socio-economic life. Eur. J. Mark. Econ. 2(2), 69-74 (2019b)

Pilat, D., Lee, F.K.: Productivity growth in ICT producing and ICT-using industries: a source of growth differentials in the OECD?. OECD Science, Technology and Industry Working Papers 04, OECD Publishing, Paris (2001). https://doi.org/10.1787/774576300121

Pirtea, M., Nicolescu, C., Botoc, C.: Do Romanian Companies Follow Pecking Order Financing? Econ. Comput. Econ. Cybern. Stud. Res. 48(1), 1-15 (2014)

Runiewicz-Wardyn, M.: Competitiveness and wellbeing of Central Eastern European economies in the last decade. TIGER Working Paper Series 2018, 139, Transformation, Integration and Globalization Economic Research (TIGER), Warsaw (2018)

Schreyer, P.: The Contribution of Information and Communication Technology to Output Growth: A Study of the G7 Countries. STI Working Paper 2, Organisation for Economic Cooperation and Development, Paris (2000)

Schuller, B.J., Lidbom, M.: Competitiveness of Nations in the Global Economy. Is Europe internationally competitive? Econ. Manag. 14, 934-939 (2009)

Schwab, K., Sala-i-Martin, X. et al.: Key findings of the Global Competitiveness Index. The Global Competitiveness Report 2016-2017. http://www3.weforum.org/docs/GCR2016-2017/05FullReport/TheGl obalCompetitivenessReport2016-2017_FINAL.pdf (2017). Accessed 2 Mar 2020

Şener, S., Saridogan, E.: The effects of science-technology-innovation on competitiveness and economic growth. Procedia-Soc. Behav. Sci. 24, 815-828 (2011)

Simionescu, M., Lazányi, K., Sopková, G., Dobeš, K., Balcerzak, A.P.: Determinants of economic growth in V4 countries and Romania. J. Compet. 9(1), 103-116 (2017). https://doi.org/10.7441/joc.2017.01.07

Sum, N.L., Jessop, B.: Competitiveness, the knowledge-based economy and higher education. J. Knowl. Econ. 4, 24-44 (2013). https://doi.org/10.1007/s13132-012-0121-8

Voinescu, R., Moisoiu, C.: Competitiveness, theoretical and policy approaches. Towards a more competitive EU. Procedia Econ. Finance 22, 512-521 (2015)

Weggeman, M.: Knowledge Management in Practice. Schiedam Scriptum, Holland (2000)

World Economic Forum: http://www3.weforum.org/docs/GCR2016-2017/05FullReport/TheGlobalCompet itivenessReport2016-2017_FINAL.pdf (2017) Accessed 2 Mar 2020

Publisher's Note Springer Nature remains neutral with regard to jurisdictional claims in published maps and institutional affiliations. 


\section{Affiliations}

\section{Gratiela Georgiana Noja ${ }^{1}$ (D) - Alexandru Buglea ${ }^{2}$ - Ion Lala-Popa ${ }^{2}$. Cecilia Nicoleta Jurcut ${ }^{2}$}

Alexandru Buglea

alexandru.buglea@e-uvt.ro

Ion Lala-Popa

ion.lala@e-uvt.ro

Cecilia Nicoleta Jurcut

cecilia.jurcut@e-uvt.ro

1 Department of Marketing and International Economic Relations, Faculty of Economics and Business Administration, West University of Timisoara, 16 Pestalozzi Street, 300115 Timisoara, Romania

2 Department of Management, Faculty of Economics and Business Administration, West University of Timisoara, 16 Pestalozzi Street, 300115 Timisoara, Romania 